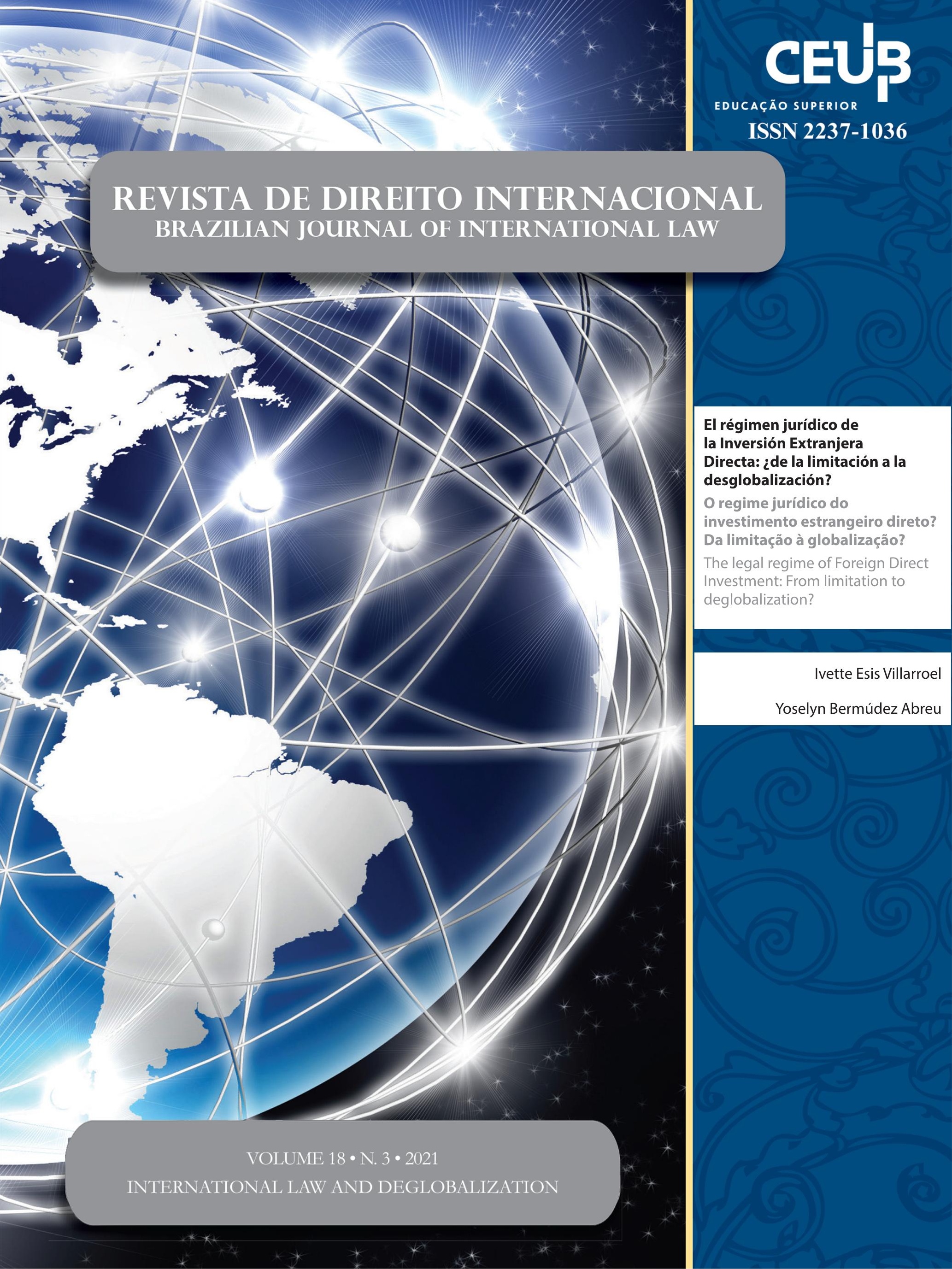




\section{Sumário}

Dossiê

EDITORIAL: INTERNATIONAL LAW AND DE-GLOBALIZATION 16 Ivette Esis, Jaime Tijmes e Juan Enrique Serrano

El régimen jurídico de la Inversión Extranjera Directa: ¿De la limitación a la desGLOBALIZACIÓN?

Ivette Esis Villarroel e Yoselyn Bermúdez Abreu

Desglobalização, Brexit e os novos acordos entre Reino Unido e União Europeia .34 Angela Limongi Alvarenga Alves e Daniel Freire e Almeida

FisCALIDAD Y DESGLOBALIZACIÓN EN UN MUNDO CRECIENTEMENTE UNILATERAL Julio César Muñiz Pérez

Covid, Covax e o Refluxo da Governança Global Salem Hikmat Nasser e Luiza Nogueira Papy

The International Monetary Fund and COVID-19: Old and New Challenges of a Post-World War II INTERNATIONAL INSTITUTION

Virdzhiniya Petrova Georgieva

Artigos Sobre outros temas

RULE OF LAW IN THE INTERNATIONAL ARENA: THE IMPORTANCE OF PRACTICES OF LEGALITY . 112 Angela Jank Calixto

THE WITHDRAWAL OF MEMBER-STATES FROM HUMAN RIGHTS COURTS: IS THE JUDICIALIZATION OF MEGA-POLITICS A NECESSARY CONDITION?. 132

Mikelli Marzzini Lucas Alves Ribeiro e Ernani Rodrigues de Carvalho Neto 
Princípio da precaução e mudança climática: uma análise do Acordo de Paris e das Conferências das Partes.

Jamille Bergamaschine Mata Diz e Carolina Mendonça de Siqueira

A INTERAÇÃo ENTRE OS ESPAÇOS CONSTITUCIONAIS NACIONAIS E INTERNACIONAIS E SEUS IMPACTOS NO SISTEMA DE FONTES DO DIREITO: AS LIÇÕES DA PROTEÇÃO COOPERATIVA DE DIREITOS HUMANOS E O CASO DA INTEGRAÇÃO EUROPEIA ...................................................... 173

Diego Fernandes Guimarães

WTO’s Engagement with National Law: Three Illustrations from India 193 Ravindra Pratap

GESTÃo MIGRATÓRIA E INTEGRAÇÃo REGIONAL: UMA ANÁLISE SOBRE A REGULAMENTAÇÃo NORmativa dos fluxos migratórios irregulares na União Europeia À luz do Novo Pacto Europeu sobre Migração e Asilo.................................................................. 212 João Mauricio Malta Cavalcante Filho e Eugênia Cristina Nilsen Ribeiro Barza

The African Regional Human and Peoples' Rights System: 40 years of progress and CHALLENGES. 232 Juan Bautista Cartes Rodríguez

The USMCA Sunset Clause 258 Jaime Tijmes-Ihl e Yvonne Georgina Tovar Silva

REFLEXÕES SOBRE A UNIVERSALIDADE DO DIREITO INTERNACIONAL DOS DIREITOS HUMANOS A RESPEITO DA PROTEÇÃO ÀS MULHERES 273 Érica Rios de Carvalho

A CRItical legal anAlysis OF GENDER EQUALITY IN INTERNATIONAL TRADE AgREEMENTS...287 Parul Shukla e Sheikh Sultan Aadil Huque

FEMinicídio, FEMicídio E Ódio NA AGENDA: o ASSASSinAto DAS MUlHERES NA AmÉriCA LATINA...... 309 Vinícius Ferreira Baptista

LEGAL IDEOLOGY IN THE CONTEXT OF DEVELOPMENT OF THE LEGAL STATE AND FORMATION OF THE CIVIL SOCIETY IN UKRAINE 
Direito INTERNACIONAL PÚBLICO NO ENTREgUERRAS (1919-39): A INSTITUCIONALIZAÇÃO DOS PROJETOS JURÍDICOS DE PAZ E MANEJO DOS POVOS NÃO SOBERANOS.

Hugo Luís Pena Ferreira

O Caso Gomes Lund (“Guerrilha Do Araguaia”) dez anos depois: Desafios para o cumPRIMENTO INTEGRAL PELO ESTADO BRASILEIRO

João Gabriel Archegas, Felipe Klein Gussoli e Vivian Cristina Lima López Valle

DiÁlogos museológicos: o Regime jurídico brasileiro e o Código de Ética do ConseLHo InTERnacional de Museus.

Paula Gonçalves do Carmo, Emerson Gabardo e Daniel Wunder Hachem 


\title{
El régimen jurídico de la Inversión Extranjera Directa: ¿de la limitación a la desglobalización?*
}

\author{
O regime jurídico do investimento \\ estrangeiro direto? Da limitação à \\ globalização?
}

\section{The legal regime of Foreign Direct Investment: From limitation to deglobalization?}

Ivette Esis Villarroel ${ }^{* *}$

Yoselyn Bermúdez Abreu***

\section{Resumen}

La libre circulación de bienes, servicios y personas gracias a la globalización ha traído como consecuencia un desarrollo socioeconómico sin precedentes en los países. Además de las operaciones comerciales transfronterizas, el flujo de Inversión Extranjera Directa ha sido clave en la generación de empleos y en el mejoramiento del capital humano. Sin embargo, este proceso ha tenido también externalidades negativas. En esta última década, se ha observado un cambio de paradigma en los Estados y su forma de interactuar con sus pares frente a tales consecuencias, lo que también ha permeado en el ámbito de las inversiones foráneas. Ante nuevas soluciones legislativas y convencionales que limitan el tipo de Inversión Extranjera Directa e incluso su libre circulación, justificadas por razones de seguridad nacional, cuidado al medio ambiente o de la salud colectiva, este artículo responde a la interrogante sobre estamos o no en presencia de una fase inicial del proceso de "desglobalización" en esta materia.

Palabras clave: Globalización; Inversión Extranjera Directa; Limitación; Desglobalización; Tratados de inversión. Finis Terrae, Chile). Doctora en Derecho (Universidad de Valencia, España). Postdoctorado en Derecho (Centro Universitário de Brasília e Universidade Federal de Uberlândia). Este trabajo forma parte del Proyecto Fondecyt Iniciación No. 11190168 sobre "Protección de la inversión chilena en el exterior frente al riesgo de expropiaciones indirectas", del cual la autora es Investigadora Responsable.

E-mail: ivette.esis.edu@gmail.com

*** Postdoctoranda en Ciencias Humanas (La Universidad del Zulia). Doctora en Derecho. Magister en Derecho Mercantil. Abogada. Docente e investigadora adscrita al Centro de Investigaciones de Derecho Privado (La Universidad del Zulia, Venezuela).

E-mail: yoselynbermudez@hotmail.com

\section{Abstract}

The free movement of goods, services and people thanks to globalization had resulted in unprecedented socio-economic development in countries. In addition to international commercial operations, the Foreign Direct Investment flow has been key in creating jobs and improving human capital. However, it is no less true that this process has also had negative externalities. In this last decade, a paradigm move has been observed in the States and their way of interacting with their partners in face of such consequences, which has also permeated the field of foreign investment. Challenged 
with new legislative and conventional solutions that limit the type of Foreign Direct Investment and even its free circulation, justified by reasons of national security, care for the environment or collective health, this article responses the question about whether or not we are in the presence of an initial phase of "deglobalization" process in this field.

Keywords: Globalization; Foreign Direct Investment; Limits; Deglobalization; Investment treaties.

\section{Resumo}

A livre circulação de bens, serviços e pessoas graças à globalização tem trazido como consequência o desenvolvimento socioeconómico sem precedentes dos países. Além das operações comerciais internacionais, o fluxo de Investimento Estrangeiro Direto tem sido clave na geração de empregos e do melhoramento de capital humano. Mas, devemos advertir que esse processo tem produzido externalidades negativas. $\mathrm{Na}$ última década, apresenta-se uma mudança de paradigmas entre os Estados e da forma de interagir entre eles na frente dessas consequências, o que também atinge ao âmbito dos investimentos estrangeiros. Perante as novas soluções nacionais e convencionais que limitam o tipo de Investimento Estrangeiro Direto, e até sua livre circulação, por causa da segurança nacional, cuidado ao meio ambiente o da saúde coletiva, esse artigo apresenta uma resposta a questão sobre se está acontecendo ou não uma fase inicial do processo de "desglobalização" nesse âmbito.

Palavras-chave: Globalização; Investimento Estrangeiro Direto; Limitações; Desglobalização; Tratados de investimentos.

\section{Introducción}

Durante años, la libre circulación de bienes, servicios y personas a través de las distintas jurisdicciones y mercados ha sido pieza clave en el desarrollo socioeconómico de los países. Así, mientras países tradicionalmente importadores de capital foráneo han hecho todo lo posible para competir entre sí y atraer la Inversión Extranjera Directa (en adelante IED), los operadores económicos -y, de ellos, los inversionistas- buscan nue- vos nichos de mercados para diversificar sus negocios y expandir sus actividades. No es casual que sus países de origen -denominados exportadores de capital- negocien con los Estados anfitriones -y captadores de dicho capital foráneo- para llegar a acuerdos y celebrar tratados de inversión o tratados de libre comercio con disposiciones especiales en esta materia, con el objetivo de brindar a las partes seguridad jurídica. En efecto, hasta la fecha de redacción de este trabajo se contabilizan más de 3000 acuerdos de este tipo. ${ }^{1}$

Sin embargo, durante los últimos tiempos hemos sido testigo de un cambio de paradigmas en los propios Estados y su forma de interactuar con sus pares. El comercio internacional ha tenido etapas de aceleración y de desaceleración. En la actualidad, producto de la pandemia del Covid-19, estamos pasando por un proceso de ralentización económica muy importante. Pero, en paralelo a esta situación, los Estados han sido más cautelosos y conscientes respecto al tipo de IED que desean atraer, en atención a sus propios procesos de desarrollo y respeto a objetivos de política pública. Frente a estos hechos, nos preguntamos: ¿estamos en presencia de un proceso de "desglobalización" en el ámbito de las inversiones foráneas?

Para responder esta interrogante, a través del estudio de legislaciones nacionales y tratados especiales, este trabajo tiene como propósito analizar la existencia de reservas o de restricciones a la IED y determinar si dichas reservas constituyen una fase de la denominada “desglobalización". De ahí que este artículo presenta los antecedentes de la globalización económica y de IED, así como el proceso de “desglobalización”. Y, luego, son revisadas las principales iniciativas legislativas de países sobre la IED, así como ciertos cambios incorporados en los tratados especiales en esta materia, para responder la problemática planteada.

\footnotetext{
1 Conferencia de Naciones Unidas para el Comercio y el Desarrollo (Unctad) revela en su portal investmentpolicyhub.unctad.org que, para mayo de 2021, existen más de 2852 tratados bilaterales de inversión y alrededor de 417 tratados con disposiciones en la materia. Véase: https://investmentpolicy.unctad.org/internationalinvestment-agreements
} 


\section{Antecedentes de la globalización económica y la IED}

La globalización económica comenzó a desarrollarse durante los años 1870 y 1940, con el nacimiento de la economía mundial moderna a través de un proceso de convergencia donde participaron las naciones europeas, Japón y Estados Unidos. ${ }^{2}$ Además, comprende altos niveles de intercambio comercial internacional entre países y empresas foráneas que aplican la $\operatorname{IED}^{3}$ y otros tipos de intercambios ya sean de capitales, tecnologías, mercancías, mano de obra, materias primas y prácticas institucionales efectivas. ${ }^{4}$

Esas relaciones estatales con empresas o inversores extranjeros tuvieron como auténtico propósito ampliar el margen de satisfacción de las necesidades humanas y lograr bienestar social, ${ }^{5}$ con base en la cooperación internacional y las ventajas comparativas. Por ello, la actividad mercantil transfronteriza se ancló en la IED, facilitada por la disminución de las fronteras nacionales entre los Estados y la aparición de circuitos internacio-

\footnotetext{
2 COPPELLI ORTIZ, Eduardo. La globalización económica del siglo XXI: entre la mundialización y la desglobalización. Estudios Internacionales, Chile, n. 191, p. 57-80, 2018. Disponible en: https:// revistaei.uchile.cl/index.php/REI/article/view/52048/57285 Acceso en: 4 ene. 2021.

3 La inversión extranjera directa es una categoría de inversión transfronteriza que realiza un residente de una economía (el inversor directo), con el objetivo de establecer un interés duradero en una empresa residente (de inversión directa), en una economía diferente de la del inversor directo. La motivación del inversor directo es establecer una relación estratégica de largo plazo con la empresa de inversión directa para garantizar un nivel significativo de influencia por parte del inversor en la gestión de la empresa de inversión directa. ORGANIZACIÓN PARA LA COOPERACIÓN Y EL DESARROLlO ECONÓMICO. Definición Marco de Inversión Extranjera Directa. 2010. Disponible en: https://www.oecd.org/ daf/inv/investmentstatisticsandanalysis/46226782.pdf Acceso en: 10 ene. 2020. Se distingue de la inversión financiera, pues la IED versa sobre: “...recursos productivos provenientes del exterior, que se instalan en un determinado país, para producir bienes o servicios con capital de riesgo, créditos asociados, tecnología, acceso a canales de comercialización internacionales y capacidad de gestión". FFRENCH-DAVIS, Ricardo. Globalización económica y desarrollo nacional: evolución y algunos desafíos actuales. Estudios Internacionales, Chile, p. 89-112, 2017.

${ }^{4}$ VERBEKE, Alain; COEURDEROY, Regis; MATT, Tanja. The future of international business research on corporate globalization that never was. Journal of International Business Studies Academy of International Business, n. 49, p. 1101-1112, 2018.

5 BADENI, Gregorio. La desglobalización en el siglo XXI. 2017. Disponible en: https://www.ancmyp.org.ar/user/files/17-BADENI. pdf Acceso en: 7 ene. 2021.
}

nales de producción y consumo, ${ }^{6}$ en la dinámica de un mercado global que conllevó a la dependencia económica.

Después de la Segunda Guerra Mundial finalizada en 1945 y hasta 1970, la explotación de recursos naturales fue desmesurada, lo que elevó tanto el nivel de la actividad industrial en los países desarrollados, como los movimientos de exportación e importación. Esto permitió el surgimiento de las empresas multinacionales, además del auge de la banca y las finanzas internacionales, resultando el aumento del bienestar de las personas. Si bien la globalización no ha conseguido acabar con la pobreza en el mundo, ${ }^{7}$ sí la ha reducido de forma significativa. ${ }^{8}$

A finales de la década de los ochenta y comienzos de los noventa del Siglo XX, la globalización económica se caracterizó por desarrollarse bajo el modelo económico liberal propuesto por el Consenso de Washington, ${ }^{9}$ aplicado por organismos financieros multilaterales como el Fondo Monetario Internacional y el Banco Mundial. Este acuerdo consistió en el requerimiento de componentes básicos de un programa aplicable a las economías en desarrollo. ${ }^{10}$ Algunos de ellos correspondieron a: la apertura hacia el comercio transfronterizo mediante rebajas impositivas, la readecuación de barreras no arancelarias, el flujo y reflujo de capitales, la estandarización \begin{tabular}{l}
\hline MESINO RIVERO, Ledis. La globalización económica y sus \\
implicaciones socio-culturales en América Latina. Revista de Ciencias \\
Sociales, Maracaibo, v. 15, n. 1, p. 126-138, mar. 2009. Disponible \\
em: http://ve.scielo.org/scielo.php?script=sci_arttext\&pid=S1315- \\
95182009000100009 \&lng=es\&nrm=iso Acceso en: 18 dic. 2020. \\
7 La globalización ha provocado resultados desequilibrados, tanto \\
entre países como dentro de los mismos. Se crea riqueza, pero hay \\
países y población que no comparten sus beneficios. STIGLITZ, \\
Joseph E. Las dos caras de la globalización. Pluralidady consenso, v. 5 , \\
n. 25, p. 172-177, 2015. \\
8 JIMÉNEZ REDONDO, Juan. Globalización y desglobalización: in- \\
seguridad y decepción en las sociedades posmodernas actuales, \\
2017. Disponible en: https://repositorioinstitucional.ceu.es/bit- \\
stream/10637/8410/1/Globalizaci\%C3\%B3n_JCJimenezRedon- \\
do_FH\%26CCCEU_2017.pdf. Acceso en: 10 ene. 2021. \\
9 Fue el economista británico John Williamson quien en 1989 \\
enunció una serie de medidas de estabilización y ajustes económi- \\
cos sobre instituciones con sede en Washington (como el FMI y el \\
BM, el gobierno y la Reserva Federal de EE.UU.) sobre las cuales \\
hubo consenso sobre su necesidad. BIDAURRATZAGA, Eduar- \\
do. Consenso de Washington. Disponible en: https://omal.info/spip. \\
php?article4820 Acceso en: 4 ene. 2021. Asimismo, se postuló, im- \\
plementar una apertura comercial para dirigir a los países hacia el \\
crecimiento y desarrollo económico. \\
10 MORANDÉ, Felipe. A casi cuatro décadas del Consenso de \\
Washington ¿Cuál es su legado en América Latina? Estudios Inter- \\
nacionales, Chile, n. 185, p. 31-58, 2016.
\end{tabular} 
de los modelos económicos aplicables ${ }^{11}$ la privatización de empresas públicas y, sobre todo, el incremento de la IED $^{12}$ con fines productivos a través de compañías transnacionales, constituyendo uno de los motores del progreso, especialmente para las naciones receptoras.

La liberalización del comercio internacional se hizo viable por las condiciones económicas favorables otorgadas por los Estados, para el desarrollo e incremento de la IED en sus territorios nacionales, así como por los avances derivados de la revolución tecnológica y el acceso a la información, permitiendo que las empresas contaran con una actividad global, administrada de manera centralizada. Esto se combinó con la formulación por parte de los entes estatales de normas jurídicas abiertas y políticas que promovieron la inversión extranjera, hasta ese entonces, en un entorno de aceptación de los beneficios generados por esta. ${ }^{13}$

En este contexto, la globalización económica ha sido un proceso irreversible de gran impacto en la humanidad. Algunos de sus aspectos positivos son: su contribución con la integración entre los Estados, la inyección de capital y tecnología foránea ${ }^{14}$ que coadyuvan al desarrollo y mejoramiento de la economía nacional mediante el incremento de fuentes de empleo, la capacitación de recursos humanos, la libre circulación de mercancías, el acceso a los bienes y servicios, y en el comercio internacional en general la producción a mayor escala y a bajo costo, haciendo posible la expansión del intercambio transfronterizo, lo que permitió incrementar la riqueza en el mundo.

Pero, a su vez, la aceleración del proceso de globalización económica impactó negativamente sobre la libertad, dignidad y progreso de la humanidad. ${ }^{15}$ Se profun-

\footnotetext{
${ }^{11}$ COPPELLI ORTIZ, Eduardo. La globalización económica del siglo XXI: entre la mundialización y la desglobalización. Estudios Internacionales, Chile, n. 191, p. 57-80, 2018. Disponible en: https:// revistaei.uchile.cl/index.php/REI/article/view/52048/57285 Acceso en: 4 ene. 2021.

12 Véanse los datos sobre el desarrollo de la IED en el período comprendido entre 1970 y 1990. Es a partir del año 1986 cuando comienza su proceso de aceleración hasta llegar a la cúspide (con variaciones) en el año 2007.

13 ESPLUGUES MOTA, Carlos. La suspensión de la libre circulación de inversiones extranjeras en España por la crisis del Covid-19. Cuadernos de Derecho Transnacional, v. 12, n. 2, p. 372-413, oct. 2020.

14 RIVAS ACEVES, Salvador; PUEBLA MÉNEZ, Alondra Donají. Inversión extranjera directa y crecimiento económico. Revista Mexicana de Economia y Finanzas, v. 11, n. 2, p. 51-75, 2016.

15 BADENI, Gregorio. La desglobalización en el siglo XXI. 2017. Dis-
}

dizaron desigualdades entre las personas, las naciones y, además, se produjeron graves daños al medio ambiente. Ello, como consecuencia de la permisividad normativa (la formulación de preceptos jurídicos que favorecieran la IED) por parte de los Estados (en su mayoría, los subdesarrollados). Por lo expuesto, las normas jurídicas relativas a la IED están siendo objeto de revisión y rediseño para mejorar su potencial en resguardo de la presente y las futuras generaciones.

\section{La desglobalización: hacia el deber ser de la actividad económica mundial}

Las bases de la globalización económica sobre las cuales se desarrolló la IED, como la apertura de los mercados y las políticas nacionales e internacionales por parte de los gobiernos de liberalizar sus economías, se debilitaron considerablemente. ${ }^{16}$ A partir del nuevo milenio, el comercio internacional se ralentizó y por los cambios que se vienen presentando, desde el punto de vista jurídico normativo, no se avizora su aceleración sino la reforma de los sistemas regulatorios en materia de IED. La mirada es hacia la revisión o restricción de los excesos de la globalización para lograr un acertado equilibrio entre las esferas que actúan en la actividad mercantil mundial. Se trata de tener una visión cautelosa sobre la libre circulación de inversiones extranjeras, que se plasma en la elaboración de normativas más restrictivas. ${ }^{17}$

$\mathrm{Al}$ respecto, cabe señalar que la globalización es un proceso espontáneo, móvil y continuo, ${ }^{18}$ caracterizado

ponible en: https://www.ancmyp.org.ar/user/files/17-BADENI. pdf Acceso en: 7 ene. 2021.

16 JALIFE RAHME, Alfredo. Hacia la desglobalización. México: Jorales Editores, 2007. Disponible en: https://www.cibertlan.net/ biblio/a_jalife/a_jalife.hacia_la_desglobalizacion_05.pdf Acceso en: 18 ene. 2020

17 ESPLUGUES MOTA, Carlos. Libre circulación de inversiones en la Unión Europea en tiempos de COVID-19. Revista Derecho \& Justicia, v. 3, n. 1, p. 99-139, 2020.

18 A partir de los setenta del siglo pasado, la globalización ha pasado por fases en las que ha crecido, decrecido o mutado, en respuesta a cambios en la economía y geopolítica mundiales por el auge de las potencias emergentes asiáticas y el cambio del epicentro de la actividad mundial del Atlántico al Pacífico. OLIVIÉ, Iliana; GRACIA, Manuel. ¿El fin de la globalización? una reflexión sobre los efectos de la crisis del COVID-19 desde el Índice Elcano de Presencia Global. Disponible en: http://www.realinstitutoelcano.org/wps/portal/ rielcano_es/contenido?WCM_GLOBAL_CONTEXT=/elcano/ elcano_es/zonas_es/ari43-2020-olivie-gracia-fin-de-la-globaliza- 
principalmente por la apertura de las fronteras, el acercamiento entre personas, el acceso a la información y a los bienes, y el incremento en la prestación de servicios que, de algún modo, han contribuido con el bienestar de la sociedad. Como proceso no reglado, característica normal de un fenómeno social y de amplia envergadura, actualmente se ve trastocado en su permisividad (que provocó o incrementó situaciones negativas para la libertad, dignidad y progreso de la humanidad ${ }^{19}$ ).

A tenor de lo expuesto, los Estados vienen aplicando limitaciones necesarias, propias de lo que se llama desglobalización ${ }^{20}$ (entiéndase en su noción más amplia como una revisión o alteración a la normal y acelerada actividad económica mundial). Una especie de estadio momentáneo propio de la avasallante globalización, pues el mundo subyace en este indetenible proceso. La globalización es el todo y la desglobalización es parte necesaria de ese todo. En efecto, se considera que la desglobalización desde el punto de vista económico tiene fases o etapas desde el replanteamiento hasta la reducción significativa de las relaciones entre los países y entre los agentes económicos ${ }^{21}$.

$\mathrm{Al}$ respecto, surgen interrogantes como: ¿Qué va a pasar en el mundo con las limitaciones aplicadas a la IED, si esta es una de las bases de la globalización económica? ¿Las economías de los Estados serán en adelante nacionalistas o proteccionistas? ¿Con las limitantes a la IED se retrotraerán las naciones a una economía cerrada? Cualquiera que sea la respuesta, por los momentos es un punto y aparte en la historia de este proceso

cion-reflexion-efectos-crisis-covid-19-indice-ecano-de-presenciaglobal Acceso en: 14 mar. 2021.

19 BADENI, Gregorio. La desglobalización en el siglo XXI. 2017. Disponible en: https://www.ancmyp.org.ar/user/files/17-BADENI. pdf Acceso en: 7 ene. 2021.

${ }^{20}$ La desglobalización es retomar la noción del proteccionismo por parte de los Estados como respuesta a la globalización económica que no logró efectos equitativos entre las personas y las naciones del mundo. SAPIR, Jacques. La démondialisation. Paris: Editions du Seuil, 2011. Disponible en: http://ekladata.com/qCMpnHCs71H2aM95aBc5H3ZgCBI.pdf Acceso en: 17 ene. 2021. Asimismo, se contrapone al libre comercio y a su desregulación responsables de afectar los derechos sociales de las personas y el medio ambiente. BELLO, Walden. Deglobalization, ideas for a New World Economy, Londres y Nueva York: Zed Books, 2004.

${ }^{21}$ OLIVIÉ, Iliana; GRACIA, Manuel. ¿El fin de la globalización? una reflexión sobre los efectos de la crisis del COVID-19 desde el Índice Elcano de Presencia Global. Disponible en: http://www. realinstitutoelcano.org/wps/portal/rielcano_es/contenido?WCM_ GLOBAL_CONTEXT=/elcano/elcano_es/zonas_es/ari432020-olivie-gracia-fin-de-la-globalizacion-reflexion-efectos-crisiscovid-19-indice-ecano-de-presencia-global Acceso en: 14 mar. 2021. tan inmenso como el mar, e intentar frenarlo equivaldría a poner un dique a sus aguas sabiendo que por otros lados se desbordarán. La globalización general -no solo la económica- es indetenible y tendrá otras vertientes que, como ha sucedido en todo momento, son impredecibles (por ejemplo, ante las condiciones que se están aplicando a la globalización física se ha comenzado a desarrollar la digital o en línea). En cambio, la desglobalización es un período aislado y acotado, que no marca ni el futuro inmediato ni el largo plazo de la globalización. $^{22}$

En respuesta a lo anterior, bajo el amparo de las telecomunicaciones, el desarrollo tecnológico, el acceso a la información y las finanzas internacionales, existen y existirán otros tipos de inversiones extranjeras entre los países que prevén diversos niveles de interdependencia o integración ${ }^{23}$ (a pesar del emergente nacionalismo económico). La IED quedará limitada o condicionada al deber ser. Comenzó a ser, desde ya, otro concepto; en todo caso, menos liberal, donde los Estados receptores de la IED expondrán su madurez comercial mediante la aplicación de una serie de medidas sociales y jurídicas en resguardo de sus intereses.

Es el momento de reflexionar y reivindicar desde el punto de vista humano, lo que es esencial para el hombre, su entorno natural y el respeto a sus derechos fundamentales. Es una exigencia desglobalizar al planeta con el objeto de hallar la resurrección humanista en una economía mundial ${ }^{24}$ más holística y biosférica. ${ }^{25}$ Es pensar con el firme propósito de reconstruir una integración que tenga en su centro a los pueblos y a la naturaleza, ${ }^{26}$

22 COPPELLI ORTIZ, Eduardo. La globalización económica del siglo XXI: entre la mundialización y la desglobalización. Estudios Internacionales, Chile, n. 191, p. 57-80, 2018. Disponible en: https:// revistaei.uchile.cl/index.php/REI/article/view/52048/57285 Acceso en: 4 ene. 2021.

${ }^{23}$ WITT, Michael A. Deglobalization: theories, predictions, and opportunities for international business research. Journal of International Business Studies, n. 50, p. 1053-1077, 2019.

${ }^{24}$ Aunque sobre esta percepción existan detractores que apuntan hacia una gravedad para la economía internacional con impacto social y tecnológico generando un posible estancamiento en la generación de conocimiento, procesos y productos. ORTIZ GOMEZ, Paula; RODRIGUEZ MONTENEGRO, Nicolás; ROJAS ROJAS, Andrés. Capitalismo, manifiesto de un sistema económico. 2020. Disponible en: http://hdl.handle.net/20.500.12494/18159 Acceso en: 21 may. 2021.

25 JALIFE RAHME, Alfredo. Hacia la desglobalización. México: Jorales Editores, 2007. Disponible en: https://www.cibertlan.net/ biblio/a_jalife/a_jalife.hacia_la_desglobalizacion_05.pdf Acceso en: 18 ene. 2020.

${ }^{26}$ SOLÓN, Pablo. Desglobalización: alternativas sistémicas: vivir bien, 
pues antepone la dimensión humana y ambiental en todo proceso. ${ }^{27}$

La desglobalización en sí misma es correctiva. Es el freno a la apresurada globalización de las últimas décadas. Una pausa que conlleva a repensar en torno a lo humano, en la búsqueda de lo vital y natural para alejarse de lo superfluo o material. Procura romper con el esquema de lo masivo mundial y volcarse a lo individual local. Es la pieza faltante de la globalización omnipresente, irrevocable e indetenible. Una especie de enmienda, tardía o temprana, pero necesaria, de un fenómeno desmedido que atentaba contra el hombre mismo. La globalización procura el bienestar de las personas, la desglobalización busca la protección de las personas. Por ello, la tendencia por parte de algunos Estados hacia posturas aisladas que dan una nueva perspectiva al proceso de globalización económica, con un carácter de autosuficiencia y de resguardo de los intereses locales sobre la apertura de los mercados, caracteres propios de la desglobalización. ${ }^{28}$

\section{Las medidas proteccionistas ante la IED}

Algunos de los efectos de la desglobalización consisten en el retorno hacia la aplicación de normas tributarias de estricto cumplimiento en materia de IED, la implementación de programas con repercusión social a favor de las Estados donde se desarrolle la inversión y, por supuesto, el respeto a las leyes de protección del medio ambiente. Esto refleja el despertar de los países (en su mayoría) menos desarrollados sobre las imposiciones que, en su momento, aplicaron las empresas multinacionales para poder operar en otras latitudes. Véase entonces como la oportunidad de ejecutar acuerdos co-

decrecimiento, comunes, ecofeminismo, derechos de la madre tierra y desglobalización. 2017. Disponible en: https://systemicalternatives.files.wordpress.com/2017/03/pdf-libro-sa.pdf Acceso en: 23 ene. 2021.

27 SOLÓN, Pablo. Desglobalización: alternativas sistémicas: vivir bien, decrecimiento, comunes, ecofeminismo, derechos de la madre tierra y desglobalización. 2017. Disponible en: https://systemicalternatives.files.wordpress.com/2017/03/pdf-libro-sa.pdf Acceso en: 23 ene. 2021.

${ }^{28}$ COPPELLI ORTIZ, Eduardo. La globalización económica del siglo XXI: entre la mundialización y la desglobalización. Estudios Internacionales, Chile, n. 191, p. 57-80, 2018. Disponible en: https:// revistaei.uchile.cl/index.php/REI/article/view/52048/57285 Acceso en: 4 ene. 2021. merciales equilibrados entre las naciones, con el claro propósito de evitar y atenuar las externalidades no positivas ocasionadas por el libre comercio internacional.

En este sentido, los cambios esperados son: de tipo formal, relativos a la normativa jurídica aplicable para regular la IED; y de tipo material, los vinculados con el desarrollo humano y la protección al medio ambiente. Será una dinámica paulatina pues se involucran factores de integración económica que, de algún modo, comprometen la absoluta soberanía de las naciones. Al respecto, ya se evidencian limitaciones o restricciones normativas que han disminuido la IED en cuanto a la entrada y salida neta de capitales entre los Estados. Véase el siguiente recuadro donde se observa la disminución de la IED durante los años 1970 y 2019:

Gráfico 1 - Inversión Extranjera Directa, entrada neta de capital (\% del PIB)

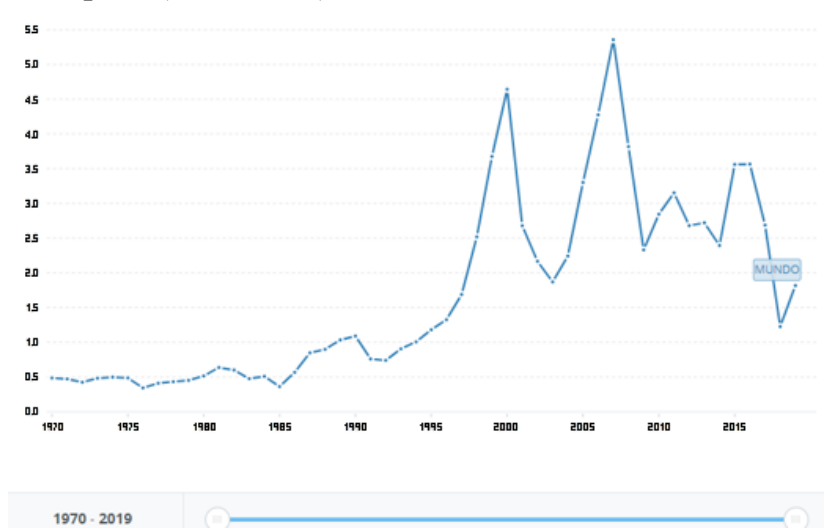

Fuente: Banco Mundial. ${ }^{29}$

29 A los efectos de este artículo se consideran los datos suministrados por organismos internacionales hasta el año 2019. Véase: Fondo Monetario Internacional, Estadísticas Financieras Internacionales y la base de datos de la balanza de pagos, Banco Mundial, Flujos Mundiales de Financiamiento para el Desarrollo, y estimaciones del PIB del Banco Mundial y la Ocde. BANCO MUNDIAL. Inversión Extranjera Directa, entrada neta de capital (\% del PIB). 2019. Disponible en: https://datos.bancomundial.org/indicator/BX.KLT.DINV. WD.GD.ZS Acceso en: 15 ene. 2021. Los datos correspondientes al año 2020 responden a un sui generis contexto económico mundial basado en la crisis de salud y de la efectividad de las políticas para mitigar los efectos económicos de la pandemia Covid19, donde las medidas de confinamiento han ralentizado los proyectos de inversión extranjera existentes y, los gobiernos han adoptado nuevas restricciones sobre la IED, pronosticándose su recuperación para el año 2022, según el Secretario General de la Unctad, Mukhisa Kituyi. UNCTAD. La Inversión Extranjera Directa mundial prevista a caer $40 \%$ en 2020, según un informe de las Naciones Unidas. 2020. Disponible en: https://unctad.org/es/press-material/la-inversion-extranjera-directa-mundial-prevista-caer-40-en-2020-segun-un-informe-de Acceso en: 15 ene. 2021. 
Sería un desafío intentar enumerar las áreas y los modos en que los Estados han incorporado limitaciones o condiciones en las normas jurídicas aplicables a la IED. Esto exigiría la revisión de cada uno de los sistemas jurídicos nacionales (labor interminable considerando la productividad normativa en las naciones del mundo). Sin embargo, podemos mencionar algunos ejemplos ilustrativos: la creación de entes administrativos ad hoc con carácter supervisor, el incremento de sanciones administrativas, así como la determinación de nuevos sectores económicos estratégicos y de un elenco de requisitos a cumplir. En este sentido, a continuación, se comentan dos materias básicas sobre las cuales los países han comenzado a aplicar medidas proteccionistas, estas son: la seguridad nacional y el medio ambiente. Ambas se analizan brevemente, por considerarlas, unas de las más importantes por la amplitud de campos que abarcan.

\subsection{Sobre la seguridad nacional}

Fue en la época de los años noventa cuando el capitalismo a través de la IED en los Estados subdesarrollados tuvo su mayor auge en materia de privatización, incluso de servicios básicos, con políticas gubernamentales que no respondían a la realidad social, más bien, a intereses económicos ajenos al bienestar común. Es así como la IED impactó en la autonomía de los países, pues existió una especie de cesión del poder soberano en la toma de decisiones a favor de empresas, foros y organismos internacionales, que establecían de modo unilateral las medidas a seguir por parte de las naciones. ${ }^{30}$

En resumen, el ascenso de un poder político global en la estructura de autoridad en los Estados del mundo, ${ }^{31}$ afectó la seguridad nacional cuando se trató de la propiedad por entes extranjeros sobre edificaciones importantes en el territorio del país receptor. Ello mostró un desequilibrio en cuanto a los beneficios económicos que obtenía esta nación, en comparación con la renta que extraía el inversor extranjero. Además, se ocasionó una dependencia sobre la tecnología básica importada y

\footnotetext{
30 COPPELLI ORTIZ, Eduardo. La globalización económica del siglo XXI: entre la mundialización y la desglobalización. Estudios Internacionales, Chile, n. 191, p. 57-80, 2018. Disponible en: https:// revistaei.uchile.cl/index.php/REI/article/view/52048/57285 Acceso en: 4 ene. 2021.

31 RAYÓN BALLESTEROS, María Concepción. La globalización: su impacto en el estado nación y en el derecho. Revista Jurídica Derecho, v. 7, n. 8, p. 19-37, 2018.
}

de productos comerciales esenciales. Más aún, era usual que estos inversionistas foráneos influyeran en la política interna de las naciones, ${ }^{32}$ lo que conllevó a pensar que, de algún modo, socavaba la democracia. ${ }^{33}$

En respuesta a ello, en la actualidad los Estados analizan las ventajas que otorga la IED en sus territorios rediseñando un nuevo modelo comercial que resguarde sus intereses sociales, económicos y políticos. El propósito es retomar el control sobre sectores estratégicos y salvaguardar la seguridad nacional. Por ejemplo, para algunas naciones la dependencia del mercado exterior en materia de bienes esenciales no tecnológicos, como los insumos médicos necesarios para contrarrestar una eventual emergencia, es contraproducente en el sentido de que se debe garantizar un mínimo de productividad en áreas básicas y no actuar bajo el sometimiento de proveedores externos. ${ }^{34}$

Es así como las naciones están llamadas a rehacer sus sectores estratégicos básicos retomando la producción nacional, ${ }^{35}$ parte elemental del proceso "desglobalizador". Esto exige un cauteloso análisis sobre la oportunidad de adquirir innovación tecnológica, para sumergirse en los cambios y oportunidades de un comercio sólido y un desarrollo sostenible, con el propósito de lograr equidad intergeneracional en el consumo de recursos. ${ }^{36}$

\subsection{Sobre el medio ambiente}

Mientras que la globalización jerarquizó los valores materiales sobre otros valores, la desglobalización se preocupa por el medio ambiente o la vida misma. ${ }^{37} \mathrm{La}$ necesidad de conservar el entorno natural en respuesta

32 MORANDÉ, Felipe. A casi cuatro décadas del Consenso de Washington ¿Cuál es su legado en América Latina? Estudios Internacionales, Chile, n. 185, p. 31-58, 2016.

33 STIGLITZ, Joseph E. Las dos caras de la globalización. Pluralidad $y$ consenso, v. 5, n. 25, p. 172-177, 2015.

34 ESPLUGUES MOTA, Carlos. La suspensión de la libre circulación de inversiones extranjeras en España por la crisis del Covid-19. Cuadernos de Derecho Transnacional, v. 12, n. 2, p. 372-413, oct. 2020.

35 LABORIE, Mario. Desglobalización y pandemia global. Documento de Opinión IEEE 28/2020, n. 18, p. 485-501, 2020. Disponible en: http://www.ieee.es/Galerias/fichero/docs_opinion/2020/ DIEEEO28_2020MARLAB_desglobalizacion.pdf Acceso en: 18 ene. 2021.

36 WARBURTON, Christopher. Trade treaties and Deglobalization. Ampliad Econometrics and International Development, v. 17-1, p. 71-91, 2017.

37 STIGLITZ, Joseph E. Las dos caras de la globalización. Pluralidad y consenso, v. 5, n. 25, p. 172-177, 2015. 
a la crisis ecológica y a la explotación desmedida de los recursos naturales en los países receptores de IED (en su mayoría subdesarrollados), ha conllevado a este proceso de desglobalización. Las actividades de extracción ilimitada que propiciaron el calentamiento global y el deterioro de la flora, fauna, ríos, relieves, entre otros, han amenazado a los seres vivos. Frente a esta situación, la preocupación estatal y de la propia ciudadanía consiste en rectificar y prevenir, ser más críticos con las concesiones sobre las IED y acatar las normas jurídicas nacionales e internacionales que tutelan la protección del medio ambiente. ${ }^{38}$ En consecuencia, las inversiones extranjeras tienden a limitarse o condicionarse, particularmente, en la administración de determinados recursos naturales. ${ }^{39}$

El presente acontecer mundial subyace sobre programas nacionales e internacionales de protección al medio ambiente. Estos programas comprenden la preservación de los recursos naturales, el ahorro energético, el uso de fuentes de energías alternas, la producción de artículos biodegradables, y un sinnúmero de medidas en pro de conservar la naturaleza. De igual modo, han establecido el camino a seguir por la humanidad, y de su cumplimiento deben y se han encargado los gobiernos, los organismos internacionales y las $\mathrm{ONG}$, por una parte. Por otra, claro está, son responsables las personas, lo que exige hábitos y conciencia social acompañados de una excelente educación ambiental. ${ }^{40}$ Sobre esto debemos aprender de las comunidades indígenas que viven en equilibrio con la naturaleza, pues su cultura e identidad se basan en la protección del medio ambiente que asegura el pleno disfrute de los derechos humanos. ${ }^{41}$

\section{El reflejo de las medidas que propenden hacia la reserva de IED en la legislación nacional de los países y en los más recientes tratados de inversión}

Según la Conferencia de Naciones Unidas para el Comercio y el Desarrollo (Unctad), la inversión extranjera global para el año 2019 ascendió a la cantidad de 1540 billones de dólares ${ }^{42}$. Sin embargo, ante la crisis sanitaria y económica generada por la pandemia, las cifras han caído drásticamente al punto que esta organización internacional anunció que el flujo de IED en 2020 bajó más de un 49\% comparado con 2019, siendo las economías de los países más desarrollados las más golpeadas y las de los menos desarrollados más resilientes ${ }^{43}$.

En fechas previas y durante la etapa de pandemia, se ha observado cierta reserva en la interrelación de los países en sus relaciones económicas, dada la promulgación de leyes que exigen el estudio o escrutinio de la IED que los Estados están dispuestos a recibir, argumentado sobre la base de la "seguridad nacional", el "cuidado del medio ambiente" e, incluso, el "resguardo de la salud colectiva" ${ }^{44}$. Esto no quiere decir que los Estados no continúen dictando leyes especiales o celebrando tratados de inversión. Por el contrario: lo hacen, pero con una mayor consciencia y preocupación por (i) atraer la inversión foránea, siempre que sea de interés y conveniencia para el Estado receptor; (ii) aumentar la reserva del poder regulatorio de los Estados en los más recientes tratados de inversión; y (iii) incorporar normas que imponen una serie de obligaciones al inversionista foráneo frente el Estado anfitrión.

\subsection{Nuevas legislaciones y medidas administrativas nacionales sobre IED}

Ciertos países ya han venido analizando la posibilidad de ir controlando el tipo de inversión extranjera

38 BADENI, Gregorio. La desglobalización en el siglo XXI. 2017. Disponible en: https://www.ancmyp.org.ar/user/files/17-BADENI. pdf Acceso en: 7 ene. 2021.

39 ESPLUGUES MOTA, Carlos. Libre circulación de inversiones en la Unión Europea en tiempos de COVID-19. Revista Derecho \& Justicia, v. 3, n. 1, p. 99-139, 2020.

40 BADENI, Gregorio. La desglobalización en el siglo XXI. 2017. Disponible en: https://www.ancmyp.org.ar/user/files/17-BADENI. pdf Acceso en: 7 ene. 2021.

${ }^{41}$ MONTOYA, Mariana. Pueblos indígenas y medio ambiente: desafíos y oportunidades para el sistema de derechos humanos de la ONU. 2017. Disponible en: https://www.universal-rights.org/lac/asuntoscontemporaneos-y-emergentes-lac/pueblos-indigenas/ Acceso en: 24 ene. 2021.

\footnotetext{
42 UNCTAD. World Investment Report 2020: international production beyond the pandemic. New York: United Nations, 2020. p. 11.

${ }^{43}$ UNCTAD. Investment trend monitor. New York/Geneva: United Nations, 2020. p. 1-4.

${ }^{44}$ COPPELLI ORTIZ, Eduardo. La globalización económica del siglo XXI: entre la mundialización y la desglobalización. Estudios Internacionales, Chile, n. 191, p. 57-80, 2018. p. 74. Disponible en: https://revistaei.uchile.cl/index.php/REI/article/view/52048/57285 Acceso en: 4 ene. 2021.
} 
en sus respectivos territorios ${ }^{45}$. En el caso de la Unión Europea (UE), el Reglamento 2019/452 del Parlamento Europeo y del Consejo de 19/03/2019 para el control de las inversiones directas extranjeras en la Unión, que entró en vigencia el pasado mes de octubre de 2020, establece que tanto la Unión como sus Estados miembros pueden adoptar medidas restrictivas a la IED, por razones de seguridad o de orden público ${ }^{46}$. Se exige, en todo caso, que los Estados administren los controles en forma transparente y no discriminatoria, garantizando el debido proceso y la tutela judicial efectiva de los inversionistas. Cada miembro debe identificar las circunstancias para los motivos, plazos, procedimientos y ejercicio de dicho control.

Conforme al artículo 4 del referido Reglamento, para la determinación de si una IED puede acarrear problemas o afecte la seguridad nacional o al orden público, los Estados y la Comisión de la UE pueden considerar sus efectos potenciales en ciertos tipos de inversión. Vale decir: infraestructuras críticas, físicas o virtuales, incluyendo terrenos e inmuebles, tecnologías críticas y productos de doble uso (inteligencia artificial y tecnología aeroespacial, entre otras), suministro de insumos esenciales (materias primas, energía y seguridad alimentaria), información sensible (datos personales) y libertad y pluralismo de los medios de comunicación. $\mathrm{El}$ abanico de materias, como puede observarse, es bastante amplio.

Siguiendo el citado artículo, en dicho examen tanto la Comisión como los Estados de la UE pueden también analizar ciertos elementos atinentes al inversor: el control directo o indirecto de un gobierno de un tercer país sobre el inversionista foráneo; la participación de dicho inversionista en actividades que atenten contra la seguridad o al orden público de un Estado de la UE o la existencia de riesgo grave de que esté ejerciendo o practicando actos ilegales o delictivos.

Todos los Estados de la UE deben presentar a la Comisión un informe anual sobre las IED que se ejecutan en el territorio, así como informar tanto a dicho ente como a los otros Estados sobre los controles que está

\footnotetext{
45 ESPLUGUES MOTA, Carlos. Libre circulación de inversiones en la Unión Europea en tiempos de COVID-19. Revista Derecho \& Justicia, v. 3, n. 1, p. 99-139, 2020.

46 UNIÓN EUROPEA. Reglamento 2019/452 del Parlamento Europeo y del Consejo de 19/03/2019 para el control de las inversiones directas extranjeras en la Unión. Disponible en: https:/ / eur-lex.europa.eu/legal-content/ES/ALL/?uri=CELEX:32019R0452 Acceso en: 25 feb. 2021.
}

ejerciendo sobre las inversiones. A su vez, los Estados pueden emitir ciertas consideraciones u observaciones respecto al control desarrollado. Igualmente, el Reglamento establece un mecanismo de cooperación con respecto a las IED que estén fuera del control. En esos casos, un Estado miembro puede emitir observaciones a otro Estado miembro sobre la eventual afectación a la seguridad o al orden público.

La Comisión puede también emitir un dictamen dirigido a un Estado donde se ha realizado una IED que afecte a los intereses de la Unión. Asimismo, se crea un grupo de expertos para el control de la inversión extranjera en la UE, junto a mecanismos de cooperación internacional con terceros países. Los Estados miembros, a efectos de la ejecución del Reglamento, nombran un punto de contacto quienes participan junto a la Comisión en todos los aspectos regulados por dicha normativa.

En este orden de ideas, no solo la UE ha dictado este tipo de normativas. En fechas recientes, UNCTAD ha advertido que varios países han promulgado leyes que limitan o restringen la inversión, en atención a la preocupación de su seguridad nacional, en particular, ante posibles adquisiciones de bienes nacionales y tecnología por parte de "inversionistas hostiles" ${ }^{47}$. Comparado con años anteriores, se estima que tales medidas aumentaron en un $43 \%$.

A título ilustrativo, en Austria fue promulgada la Foreign Direct Investment Control Act en 2020 que exige a las autoridades competentes a examinar cuidadosamente las inversiones que puedan amenazar la seguridad o el orden público ${ }^{48}$. En Canadá fue promulgada una normativa que establece la extensión de ciertos plazos de tiempo durante 2020 para que las autoridades puedan realizar el escrutinio de las inversiones extranjeras en dicho territorio, fundamentada en la seguridad nacional ${ }^{49}$.

En España, en octubre de 2020 fue promulgado el Real Decreto-ley 34/2020, de 17 de noviembre, de medidas urgentes de apoyo a la solvencia empresarial y al

\footnotetext{
47 UNCTAD. Investment Policy Monitor. New York: United Nations, 2021. p. 1.

48 AUSTRIA. Foreign Direct Investment Control Act de 24/07/2020. Disponible en: https://trade.ec.europa.eu/doclib/docs/2020/september/tradoc_158955.pdf Acceso en: 23 feb. 2021.

49 CANADÁ. Temporary extension of certain timelines in the national security review process due to Covid-19. 2020. Disponible en: https://www. ic.gc.ca/eic/site/ica-lic.nsf/eng/lk81225.html Acceso en: 4 ene. 2021.
} 
sector energético, y en materia tributaria ${ }^{50}$, que suspende el régimen de liberalización de IED en dicho país hasta el 30/06/2021. Esta restricción aplica a IED sobre empresas que coticen en España y sobre aquellas no cotizadas, siempre que el valor de la inversión supere los 500 millones de Euros, efectuadas por residentes de países de la UE y de la Asociación Europea de Libre Comercio. Mientras que, en Finlandia, atendiendo a las soluciones del mencionado Reglamento UE 452/2019, fue modificada la legislación especial denominada Act on the screening of the foreign corporate acquisitions para uniformar los criterios de revisión de la IED en dicho país ${ }^{51}$.

\subsection{Nuevos tratados de IED: hacia la protección del espacio regulatorio de los Estados y la imposición de obligaciones a los inversionistas}

En la actualidad, los Estados continúan celebrando tratados de inversión. Sin embargo, la Unctad advierte que la cantidad de acuerdos en esta materia ha ido disminuyendo si comparamos las cifras con años anteriores. En efecto, a la fecha de redacción de este trabajo, según informe de esta organización internacional entre el 1 de mayo y el 31 de diciembre de 2020, fueron celebrados al menos 15 tratados de los cuales 14 contienen disposiciones generales sobre inversión y uno responde a un tratado bilateral de promoción y protección de inversiones $^{52}$.

Uno de los aspectos destacables en la nueva generación de tratados responde a la mayor preocupación de los Estados en suscribirlos en condiciones que garanticen su desarrollo socioeconómico, atendiendo a los objetivos de desarrollo sustentable de la Agenda de Naciones Unidas de 2030 53 . Esta Agenda contiene 17

\footnotetext{
50 ESPAÑA. Real Decreto-ley 34/2020, de 17 de noviembre, de medidas urgentes de apoyo a la solvencia empresarial y al sector energético, y en materia tributaria. 2020. Disponible en: https://www.boe.es/buscar/act. php?id=BOE-A-2020-14368 Acceso en: 17 ene. 2021.

51 FINLANDIA. Act on the screening of the foreign corporate acquisitions. 2020. Disponible en: https://finlex.fi/en/laki/kaannokset/1992/ en19921612_20120172.pdf Acceso en: 17 ene. 2021; PAANAJARVI, Ami; MATINLASSI, Juhani. Amendments to the finnish rules on foreign investment control have entered into force: widening the scope of mandatory regime. Insights, 2020. Disponible en: https:// www.roschier.com/newsroom/amendments-to-the-finnish-ruleson-foreign-investment-control-have-entered-into-force-wideningthe-scope-of-mandatory-regime/ Acceso en: 14 mar. 2021.

52 UNCTAD. Investment Policy Monitor. New York: United Nations, 2021. p. 7.

53 UNCTAD. World Investment Report 2018: investment and new in-
}

objetivos en varios ámbitos, con el propósito de mejorar la calidad de vida de las personas. Aunque escapa del ámbito material de este trabajo, sí debemos indicar que su cumplimiento depende en gran medida de la interacción de la iniciativa pública y privada. En efecto, la IED se requiere para financiar tales objetivos, así como se exige que los Estados sean cuidadosos en la atracción de la inversión que más se adapte a sus intereses ${ }^{54}$ : es decir, captar la IED que propenda a la creación de energías limpias renovables, la mejora del capital humano local y, en general, que contribuya efectivamente al desarrollo sustentable del Estado receptor. Con ocasión de ello -y también dadas las lecciones que ha arrojado la práctica arbitral ${ }^{55}$ - los nuevos tratados, por un lado, contienen normas que limitan el tipo de inversión protegida en dichos acuerdos ${ }^{56}$ y reiteran la reserva del espacio regulatorio de los Estados ${ }^{57}$; y, por otro, se establecen obligaciones tanto para el Estado receptor como para el propio inversionista en aras de promover y cumplir con objetivos de responsabilidad corporativa ${ }^{58}$.

dustrial policies. Disponible en: https://unctad.org/en/PublicationsLibrary/wir2018_en.pdf Acceso en: 23 ene. 2021.

54 TORRES VOLPON, Fernanda; XAVIER JUNIOR, Ely Caetano. International Investment Agreements and the promotion of sustainable development. In: LEAL FILHO, Walter et al. (eds.). Partnerships for the goals: encyclopedia of the un sustainable development goals. Cham: Springer, 2020. p. 1-11. p. 2

${ }_{55}$ Methanex Corporation v. Estados Unidos, Laudo Arbitral de fecha 21/10/2005, arbitraje administrado bajo las reglas de arbitraje de Uncitral; Chemtura Corporation v. Canadá, Corte Permanente de Arbitraje, Caso No. 2008-01, Laudo arbitral de fecha 02/08/2010, arbitraje administrado bajo las reglas de arbitraje de Uncitral; Abengoa S.A. y COFIDES S.A. v. United Mexican States, CIADI, Caso No. ARB(AF)/09/2, Laudo arbitral de fecha 18/04/2013; Philip Morris Brands Sàrl, Philip Morris Products SA y Abal Hermanos SA v. República Oriental del Uruguay, CIADI, Caso No. ARB ARB/10/7, Laudo arbitral de fecha 08/07/2016, \$284-286; Copper Mesa Mining Corporation v. República de Ecuador, Corte Permanente de Arbitraje, Caso No. 2012-2, Laudo arbitral de fecha 15/03/2016; Perenco Ecuador Ltd. v. República de Ecuador y Empresa Estatal Petróleos del Ecuador (Petroecuador), CIADI, Caso No. ARB/08/6, Laudo arbitral de fecha 27/09/2019.

56 Los más recientes tratados de inversión excluyen de su ámbito de aplicación material las operaciones de deuda pública. UNCTAD. Recent policy, developments and key issues. Geneva: United Nations, 2017. Disponible en: http://unctad.org/en/PublicationsLibrary/wir2017_en.pdf Acceso en: 23 ene. 2021; ORTOLANI, Pietro. Are bondholders investors? sovereign debt and Investment Arbitration after Poštová. Leiden Journal of International Law, n. 30, p. 383-404, 2017. p. 383-384.

57 HERNÁNDEZ G., José Gregorio. Balance y perspectivas del Arbitraje Internacional de Inversiones. Revista Electrónica de Derecho Administrativo Venezolano, n. 10, p. 69-94, 2016. p. 74-75.

58 UNCTAD. International Investment Agreements Reform Accelerator. Doc. No. UNCTAD/DIAE/PCB/INF/2020/8. New York: United Nations, 2020. p. 29. 
En primer lugar, la reserva del referido espacio regulatorio en instrumentos internacionales de inversión - conocida como la potestad soberana reconocida bajo el Derecho Internacional por la cual el Estado puede intervenir en la economía ${ }^{59}$ - se acentúa. Esto sucede especialmente ante eventuales reclamos de inversores foráneos por expropiaciones ilegales (en muchos casos, indirectas) o la violación de alguna otra garantía material (especialmente el trato justo y equitativo), en supuestos cuando el Estado receptor dicta una medida para proteger un objetivo legítimo de política pública como el cuidado al medio ambiente o la salud colectiva ${ }^{60}$.

Varios acuerdos transfronterizos celebrados en esta última década tienden a incorporar en un artículo especial la reserva del poder regulatorio de los Estados contratantes; o incluir en el apartado del artículo sobre expropiaciones una solución conforme a la cual las medidas no discriminatorias de carácter regulatorio -dirigidas a proteger legítimos objetivos públicos como la salud pública, la seguridad, el medio ambiente, la moral pública, la protección social o de los consumidores o de la diversidad cultural- no serán consideradas como expropiaciones, salvo ciertas excepciones. Así lo han establecido, a modo ilustrativo, el Acuerdo de liberalización, promoción y protección de inversiones entre Japón y Georgia (2021) ${ }^{61}$; el Acuerdo de Cooperación y Facilitación de Inversiones entre la República Federativa de Brasil e India (2020) ${ }^{62}$; el Acuerdo de Cooperación y Facilitación de Inversiones entre la República de Ecuador y la República Federativa de Brasil (2019) ${ }^{63}$; el

59 HERNÁNDEZ G., José Gregorio. Balance y perspectivas del Arbitraje Internacional de Inversiones. Revista Electrónica de Derecho Administrativo Venezolano, n. 10, p. 69-94, 2016. p. 103.

${ }^{60}$ POLANCO LAZO, Rodrigo. Two worlds apart: the changing features of international investment agreements in Latin America. In: TANZI, Attila et al. (ed.). International investment law in Latin America: problems and prospects: derecho internacional de las inversiones en América Latina: problemas y perspectivas. Leiden: Brill Edit., 2016. p. 68-97; MARTÍNEZ-FRAGA, Pedro; RYAN REETZ, C. Public International Law: rethinking regulatory sovereignty in the global area. Cambridge: Cambridge University Press, 2015. p. 261.

${ }^{61}$ UNCTAD. Acuerdo de liberalización, promoción y protección de inversiones entre Japón y Georgia. 2021. Disponible en: https://investmentpolicy.unctad.org/international-investment-agreements/treatyfiles/6078/download Acceso en: 01 mar. 2021.

${ }^{62}$ UNCTAD. Acuerdo de Cooperación y Facilitación de Inversiones entre la República Federativa de Brasil e India. 2020. Disponible en: https:/ / investmentpolicy.unctad.org/international-investment-agreements/ treaty-files/5912/download Acceso en: 01 mar. 2021.

${ }^{63}$ UNCTAD. Acuerdo de Cooperación y Facilitación de Inversiones entre la República de Ecuadory la República Federativa de Brasil. 2019. Disponible en: https://investmentpolicy.unctad.org/international-investment-
Acuerdo Comercial entre la República de Argentina y la República de Chile (2017) ${ }^{64}$; el Protocolo Adicional de la Alianza del Pacífico $(2014)^{65}$ y el Protocolo de Cooperación y Facilitación de Inversiones Intra-Mercosur $(2017)^{66}$, entre otros.

En segundo lugar, además de la exigencia de un comportamiento diligente a los inversionistas y el cumplimiento con las normas de Derecho interno durante la larga duración con el Estado receptor, se está incorporando también en los recientes tratados el deber de implementar y respetar reglas de responsabilidad social corporativa $^{67}$. Ejemplo de esta situación corresponde al caso de los Acordos de Coooperação e Facilitação de Investimentos (ACFI) de Brasil. En algunos, como ocurre con el ACFI entre la República Federativa de Brasil y la República de Colombia y el ACFI entre la República Federativa de Brasil y Malawi (ambos de 2015), se emplaza a los Estados para adoptar medidas que exijan a los inversores a cumplir con programas de responsabilidad social que involucre planes de vinculación con los distintos grupos de interés, respeto de los derechos humanos, estímulo y creación de empleo para comunidades locales, así como la implementación y cumplimiento de reglas de gobierno corporativo. Asimismo, otros ACFIs -como el celebrado con los Emiratos Árabes Unidos (2019)- establecen que la responsabilidad recae directamente en el inversor, quien debe cumplir con los estándares más altos de desarrollo sustentable del Estado receptor, considerando las Directrices de la OCDE para las empresas multinacionales.

agreements/treaty-files/5887/download Acceso en: 01 mar. 2021. ${ }^{64}$ UNCTAD. Acuerdo Comercial entre la República de Argentina y la República de Chile. 2017. Disponible en: https://investmentpolicy.unctad.org/international-investment-agreements/treatyfiles/5661/download Acceso en: 01 mar. 2021.

65 SUBSECRETARÍA DE RELACIONES ECONÓMICAS INTERNACIONALES. Protocolo Adicional de la Alianza del Pacífico. 2014. Disponible en: https://www.subrei.gob.cl/docs/default-source/ default-document-library/protocolo-adicional-al-acuerdo-marco. pdf?sfvrsn=ee8f6eb3_0 Acceso en: 5 mar. 2021.

${ }_{66}$ UNCTAD. Protocolo de Cooperación y Facilitación de Inversiones IntraMercosur. 2017. Disponible en: https:/ investmentpolicy.unctad.org/ international-investment-agreements/treaty-files/5548/download Acceso en: 5 mar. 2021.

67 MONEBHURRUN, Nitish. Crônica do direito internacional dos investimentos. Revista de Direito Internacional, v. 12, n. 1, p. 32-38, 2015. p. 34. 


\section{Conclusiones}

El replanteamiento sobre la libre circulación de inversiones de la UE y los cambios legislativos realizados por distintos países en pro de la protección de sus intereses locales por sobre la apertura de mercados, dan cuenta de la existencia de una fase inicial de desglobalización. El análisis tanto de las leyes nacionales como de las nuevas soluciones convencionales en materia de inversiones arroja una visión estatal más precavida.

La imposición de filtros o controles a la IED justificada por razones de "seguridad nacional", el "cuidado del medio ambiente" o el "resguardo de la salud colectiva", así como la reserva de espacios regulatorios, ha ido en aumento especialmente en tiempos de pandemia. La preocupación de los Estados en este ámbito también se refleja en el tipo de inversión foránea que se desea atraer y, en particular, en captar aquella que realmente apoye a su propio desarrollo socioeconómico. Además, se compromete al inversionista en este proceso, no solo por el cumplimiento voluntario a las normas y estándares del Estado receptor, sino también a través de la incorporación en los tratados de nueva generación de reglas de responsabilidad social corporativa.

Sin embargo, debemos también advertir que esta fase inicial de desglobalización no tiene carácter universal. No todos los Estados están adoptando políticas restrictivas. Por el contrario, y tal como refiere la Unctad, hay otros que continúan y mantienen sus políticas de apertura y atracción de IED. Aún falta por ver las consecuencias de la pandemia una vez que finalice, el avance de la tecnología en tiempos de crisis y si el resto de los países de la comunidad internacional se pliegan o no a este replanteamiento de prioridades y políticas públicas y legislativas en torno a la IED a futuro.

\section{Referencias}

AUSTRIA. Foreign Direct Investment Control Act de 24/07/2020. Disponible en: https://trade.ec.europa. $\mathrm{eu} /$ doclib/docs/2020/september/tradoc_158955.pdf Acceso en: 23 feb. 2021.

BADENI, Gregorio. La desglobalización en el siglo XXI. 2017. Disponible en: https://www.ancmyp.org.ar/ user/files/17-BADENI.pdf Acceso en: 7 ene. 2021.
BANCO MUNDIAL. Inversión Extranjera Directa, entrada neta de capital (\% del PIB). 2019. Disponible en: https:/ / datos.bancomundial.org/indicator/BX.KLT.DINV. WD.GD.ZS Acceso en: 15 ene. 2021.

BELLO, Walden. Deglobalization, ideas for a New World Economy, Londres y Nueva York: Zed Books, 2004.

BIDAURRATZAGA, Eduardo. Consenso de Washington. Disponible en: https://omal.info/spip.php?article4820 Acceso en: 4 ene. 2021.

CANADÁ. Temporary extension of certain timelines in the national security review process due to Covid-19. 2020. Disponible en: https://www.ic.gc.ca/eic/site/ica-lic.nsf/eng/ lk81225.html Acceso en: 4 ene. 2021.

COPPELLI ORTIZ, Eduardo. La globalización económica del siglo XXI: entre la mundialización y la desglobalización. Estudios Internacionales, Chile, n. 191, p. 57-80, 2018. Disponible en: https://revistaei.uchile. $\mathrm{cl} /$ index.php/REI/article/view/52048/57285 Acceso en: 4 ene. 2021.

ESPAÑA. Real Decreto-ley 34/2020, de 17 de noviembre, de medidas urgentes de apoyo a la solvencia empresarial y al sector energético, y en materia tributaria. 2020. Disponible en: https://www.boe.es/buscar/act.php?id=BOEA-2020-14368 Acceso en: 17 ene. 2021.

ESPLUGUES MOTA, Carlos. La suspensión de la libre circulación de inversiones extranjeras en España por la crisis del Covid-19. Cuadernos de Derecho Transnacional, v. 12, n. 2, p. 372-413, oct. 2020.

ESPLUGUES MOTA, Carlos. Libre circulación de inversiones en la Unión Europea en tiempos de COVID-19. Revista Derecho \& Justicia, v. 3, n. 1, p. 99-139, 2020.

FFRENCH-DAVIS, Ricardo. Globalización económica y desarrollo nacional: evolución y algunos desafíos actuales. Estudios Internacionales, Chile, p. 89-112, 2017.

FINLANDIA. Act on the screening of the foreign corporate acquisitions. 2020. Disponible en: https://finlex.fi/en/ laki/kaannokset/1992/en19921612_20120172.pdf Acceso en: 17 ene. 2021.

GARAY, Ane. Inversión Extranjera Directa. Omal. Disponible en: https:// omal.info/spip.php?article4822 Acceso: 10 ene. 2020.

HERNÁNDEZ G., José Gregorio. Balance y perspectivas del Arbitraje Internacional de Inversiones. Revista 
Electrónica de Derecho Administrativo Venezolano, n. 10, p. 69-94, 2016.

JALIFE RAHME, Alfredo. Hacia la desglobalización. México: Jorales Editores, 2007. Disponible en: https:// www.cibertlan.net/biblio/a_jalife/a_jalife.hacia_la_ desglobalizacion_05.pdf Acceso en: 18 ene. 2020.

JIMÉNEZ REDONDO, Juan. Globalización y desglobalización: inseguridad y decepción en las sociedades posmodernas actuales, 2017. Disponible en: https://repositorioinstitucional.ceu.es/bitstream/10637/8410/1/ Globalizaci\%C3\%B3n_JCJimenezRedondo_ FH\%26CCCEU_2017.pdf. Acceso en: 10 ene. 2021.

LABORIE, Mario. Desglobalización y pandemia global. Documento de Opinión IEEE 28/2020, n. 18, p. 485-501, 2020. Disponible en: http://www. ieee.es / Galerias / fichero/docs_opinion/2020/ DIEEEO28_2020MARLAB_desglobalizacion.pdf Acceso en: 18 ene. 2021.

MARTÍNEZ-FRAGA, Pedro; RYAN REETZ, C. Public International Law: rethinking regulatory sovereignty in the global area. Cambridge: Cambridge University Press, 2015.

MESINO RIVERO, Ledis. La globalización económica y sus implicaciones socio-culturales en América Latina. Revista de Ciencias Sociales, Maracaibo, v. 15, n. 1, p. 126-138, mar. 2009. Disponible em: http://ve.scielo. org $/$ scielo.php? script $=$ sci_arttext\&pid $=$ S131595182009000100009\&lng=es\&nrm=iso Acceso en: 18 dic. 2020.

MONEBHURRUN, Nitish. Crônica do direito internacional dos investimentos. Revista de Direito Internacional, v. 12, n. 1, p. 32-38, 2015.

MONTOYA, Mariana. Pueblos indigenas y medio ambiente: desafíos y oportunidades para el sistema de derechos humanos de la ONU. 2017. Disponible en: https:// www.universal-rights.org/lac/asuntos-contemporaneos-y-emergentes-lac/pueblos-indigenas/ Acceso en: 24 ene. 2021.

MORANDÉ, Felipe. A casi cuatro décadas del Consenso de Washington ¿Cuál es su legado en América Latina? Estudios Internacionales, Chile, n. 185, p. 31-58, 2016.

OLIVIÉ, Iliana; GRACIA, Manuel. ¿El fin de la globalización? una reflexión sobre los efectos de la crisis del COVID-19 desde el Índice Elcano de Presencia Global. Disponible en: http://www.realinstitutoelcano.
org/wps/portal/rielcano_es/contenido?WCM_GLOBAL_CONTEXT =/elcano/elcano_es/zonas_es/ ari43-2020-olivie-gracia-fin-de-la-globalizacion-reflexion-efectos-crisis-covid-19-indice-ecano-de-presenciaglobal Acceso en: 14 mar. 2021.

ORGANIZACIÓN PARA LA COOPERACIÓN Y EL DESARROLlo ECONÓMICO. Definición Marco de Inversión Extranjera Directa. 2010. Disponible en: https://www.oecd.org/daf/inv/investmentstatisticsandanalysis/46226782.pdf Acceso en: 10 ene. 2020.

ORTIZ GOMEZ, Paula; RODRIGUEZ MONTENEGRO, Nicolás; ROJAS ROJAS, Andrés. Capitalismo, manifiesto de un sistema económico. 2020. Disponible en: http://hdl.handle.net/20.500.12494/18159 Acceso en: 21 may. 2021.

ORTOLANI, Pietro. Are bondholders investors? sovereign debt and Investment Arbitration after Poštová. Leiden Journal of International Law, n. 30, p. 383-404, 2017.

PAANAJARVI, Ami; MATINLASSI, Juhani. Amendments to the finnish rules on foreign investment control have entered into force: widening the scope of mandatory regime. Insights, 2020. Disponible en: https://www.roschier.com/newsroom/amendmentsto-the-finnish-rules-on-foreign-investment-control-have-entered-into-force-widening-the-scope-of-mandatory-regime/ Acceso en: 14 mar. 2021.

POLANCO LAZO, Rodrigo. Two worlds apart: the changing features of international investment agreements in Latin America. In: TANZI, Attila et al. (ed.). International investment law in Latin America: problems and prospects: derecho internacional de las inversiones en América Latina: problemas y perspectivas. Leiden: Brill Edit., 2016. p. 68-97.

RAYÓN BALLESTEROS, María Concepción. La globalización: su impacto en el estado nación y en el derecho. Revista Jurídica Derecho, v. 7, n. 8, p. 19-37, 2018.

RIVAS ACEVES, Salvador; PUEBLA MÉNEZ, Alondra Donají. Inversión extranjera directa y crecimiento económico. Revista Mexicana de Economía y Finanzas, v. 11, n. 2, p. 51-75, 2016.

SAPIR, Jacques. La démondialisation. Paris: Editions du Seuil, 2011. Disponible en: http://ekladata.com/ qCMpnHCs71H2aM95aBc5H3ZgCBI.pdf Acceso en: 17 ene. 2021. 
SOLÓN, Pablo. Desglobalización: alternativas sistémicas: vivir bien, decrecimiento, comunes, ecofeminismo, derechos de la madre tierra y desglobalización. 2017. Disponible en: https://systemicalternatives.files.wordpress. com/2017/03/pdf-libro-sa.pdf Acceso en: 23 ene. 2021.

STIGLITZ, Joseph E. Las dos caras de la globalización. Pluralidad y consenso, v. 5, n. 25, p. 172-177, 2015.

SUBSECRETARÍA DE RELACIONES ECONÓMICAS INTERNACIONALES. Protocolo Adicional de la Alianza del Pacifico. 2014. Disponible en: https:// www.subrei.gob.cl/docs/default-source/default-document-library/protocolo-adicional-al-acuerdo-marco. pdf?sfvrsn=ee8f6eb3_0 Acceso en: 5 mar. 2021.

TORRES VOLPON, Fernanda; XAVIER JUNIOR, Ely Caetano. International Investment Agreements and the promotion of sustainable development. In: LEAL FILHO, Walter et al. (eds.). Partnerships for the goals: encyclopedia of the un sustainable development goals. Cham: Springer, 2020. p. 1-11.

UNCTAD. Acuerdo Comercial entre la República de Argentina y la República de Chile. 2017. Disponible en: https:// investmentpolicy.unctad.org/international-investmentagreements/treaty-files/5661/download Acceso en: 01 mar. 2021.

UNCTAD. Acuerdo de Cooperación y Facilitación de Inversiones entre la República Federativa de Brasil e India. 2020. Disponible en: https://investmentpolicy.unctad.org/international-investment-agreements/treaty-files/5912/ download Acceso en: 01 mar. 2021.

UNCTAD. Acuerdo de Cooperación y Facilitación de Inversiones entre la República de Ecuador y la República Federativa de Brasil. 2019. Disponible en: https://investmentpolicy.unctad.org/international-investment-agreements/ treaty-files/5887/download Acceso en: 01 mar. 2021.

UNCTAD. Acuerdo de liberalización, promoción y protección de inversiones entre Japón y Georgia. 2021. Disponible en: https://investmentpolicy.unctad.org/international-investment-agreements/treaty-files/6078/download Acceso en: 01 mar. 2021.

UNCTAD. International Investment Agreements Reform Accelerator. Doc. No. UNCTAD/DIAE/PCB/INF/2020/8. New York: United Nations, 2020.

UNCTAD. Investment Policy Monitor. New York: United Nations, 2021.
UNCTAD. Investment trend monitor. New York/Geneva: United Nations, 2020.

UNCTAD. Protocolo de Cooperación y Facilitación de Inversiones Intra-Mercosur. 2017. Disponible en: https:// investmentpolicy.unctad.org/international-investmentagreements/treaty-files/5548/download Acceso en: 5 mar. 2021.

UNCTAD. Recent policy, developments and key issues. Geneva: United Nations, 2017. Disponible en: http:// unctad.org/en/PublicationsLibrary/wir2017_en.pdf Acceso en: 23 ene. 2021.

UNCTAD. World Investment Report 2018: investment and new industrial policies. Disponible en: https://unctad. org/en/PublicationsLibrary/wir2018_en.pdf Acceso en: 23 ene. 2021.

UNCTAD. World Investment Report 2020: international production beyond the pandemic. New York: United Nations, 2020.

UNIÓN EUROPEA. Reglamento 2019/452 del Parlamento Europeo y del Consejo de 19/03/2019 para el control de las inversiones directas extranjeras en la Unión. Disponible en: https://eur-lex.europa.eu/legal-content/ES/ ALL/?uri=CELEX:32019R0452 Acceso en: 25 feb. 2021.

VERBEKE, Alain; COEURDEROY, Regis; MATT, Tanja. The future of international business research on corporate globalization that never was. Journal of International Business Studies Academy of International Business, $\mathrm{n}$. 49, p. 1101-1112, 2018.

WARBURTON, Christopher. Trade treaties and Deglobalization. Ampliad Econometrics and International Development, v. 17-1, p. 71-91, 2017.

WITT, Michael A. Deglobalization: theories, predictions, and opportunities for international business research. Journal of International Business Studies, n. 50, p. 1053-1077, 2019.

ZARRA, Giovanni. Right to regulate, margin of appreciation and proportionality: current status in investment arbitration in light of Philip Morris v. Uruguay. Revista de Direito Internacional, Brasília, v. 14, n. 2, p. 94-120, 2017. 
Para publicar na Revista de Direito Internacional, acesse o endereço eletrônico www.rdi.uniceub.br ou www.brazilianjournal.org.

Observe as normas de publicação, para facilitar e agilizar o trabalho de edição. 